\title{
TOBACCO FACTS
}

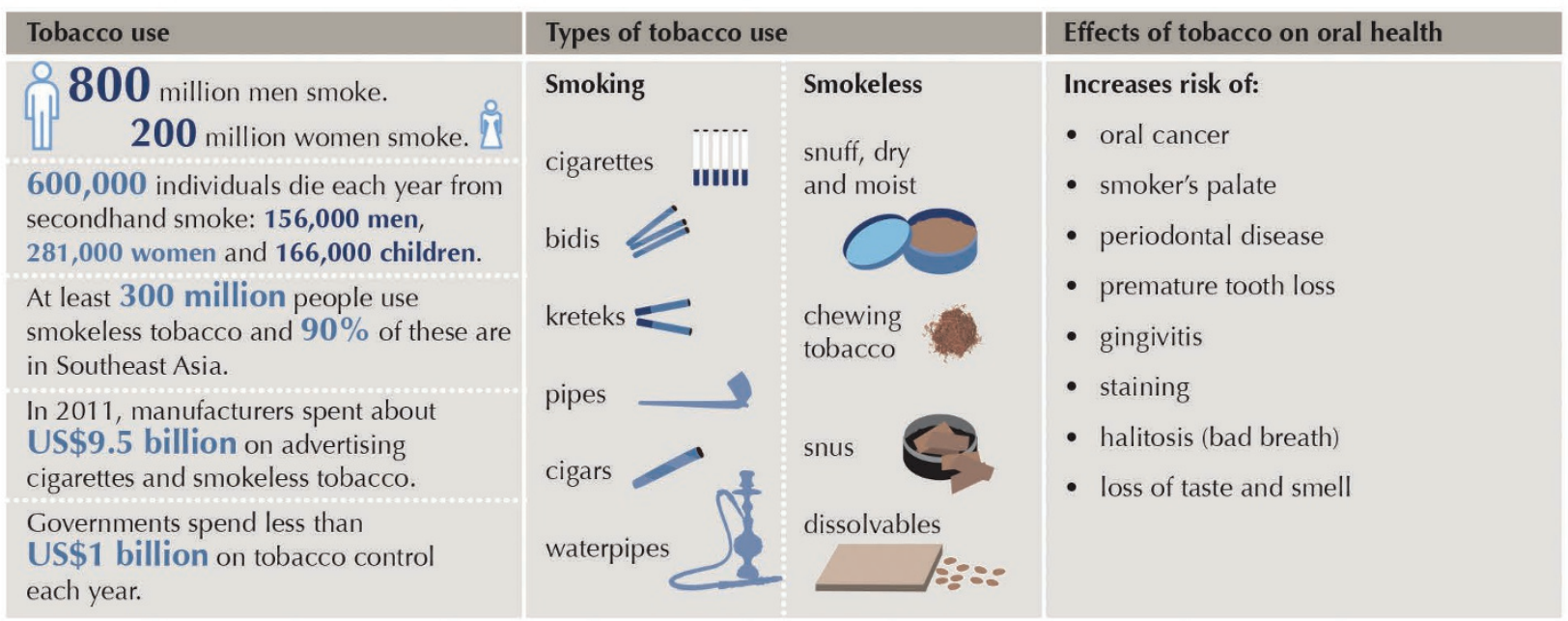

This graphic has been reproduced from The challenge of oral disease - a call for global action, the latest edition of The Oral Health Atlas published by the FDI World Dental Federation.

The new, second edition of the Atlas focuses on the policy actions related to improving prioritisation of oral health. It is available to download at http://www.fdiworldental.org/oral-health-atlas

\section{UPDATED FACULTY GUIDELINES LAUNCHED}

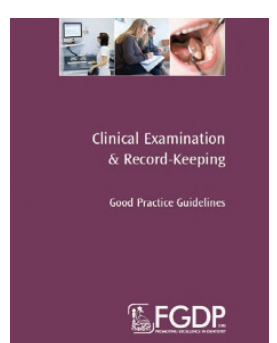

The Faculty of General Dental Practice (UK) launched the 3rd edition of its authoritative publication Clinical examination and record-keeping at the British Dental Conference and Exhibition on Friday 27 May. This is the first update to the guidelines since 2009.

The new edition introduces an $\mathrm{ABC}$ categorisation structure for recommendations, whereby an A grade recommendation is aspirational and not considered essential to good patient care, $\mathrm{B}$ is a basic requirement, and $\mathrm{C}$ is conditional upon circumstances. Through this new system the Faculty hopes to introduce greater clarity for all stakeholders.

Electronic record-keeping receives greater consideration in the new edition, reflecting the shift in record-keeping practice in recent years. Also included is revised guidance on batch numbers, and an expanded range of appendices and sample documents.

Dr Andy Hadden, a dento-legal adviser and general dental practitioner, led the team updating the guidelines, in a process that took around 18 months. The draft text was reviewed by a wide range of organisations including the British Dental Association (BDA) in the pursuit of usability, accuracy and clarity.

The definitive version of Clinical examination and recordkeeping will be freely available at www.fgdpstandards.com as a part of the Open Standards Initiative. The book version is now available for purchase, and an e-book will be available shortly. 